\title{
In Quest of a Sinoatrial Cell Model to Assess the Functional Effects of Mutations in the HCN4 Funny Current Gene
}

\author{
Ronald Wilders, Arie O Verkerk
}

Academic Medical Center, University of Amsterdam, Amsterdam, The Netherlands

\begin{abstract}
Several loss-of-function mutations in the HCN4 gene have been associated with human sinus bradycardia. The HCN4 channel underlies the hyperpolarization-activated 'funny current' $\left(I_{f}\right)$, which plays an important role in sinoatrial node (SAN) pacemaker activity.

We attempted to assess the effects of HCN4 mutations on SAN pacemaker activity through computer simulations, using the most recent comprehensive mathematical models of single SAN cells. To this end, we incorporated the experimentally identified changes in expression and kinetics of $I_{f}$ in the Severi-DiFrancesco and Maltsev-Lakatta models of a single rabbit SAN cell.

In the Severi-DiFrancesco model, 5 out of 11 mutations tested led to cessation of pacemaker activity rather than bradycardia, emphasizing the critical role of $I_{f}$ in this model. In contrast, the decrease in pacing rate amounted to a maximum of only $5.2 \%$ for the most severe mutation in the Maltsev-Lakatta model. These results became even more distinct upon replacement of the $I_{f}$ equations of either model by the ones that we recently derived from our experimental data on rabbit SAN cells.

We conclude that the most recent comprehensive mathematical models of single SAN cells do not allow adequate investigations of the functional effects of mutations in the HCN4 funny current gene.
\end{abstract}

\section{Introduction}

The hyperpolarization-activated 'funny current' ( $\left.I_{\mathrm{f}}\right)$, also known as 'pacemaker current', is a key player in sinoatrial node (SAN) pacemaker activity. This (mainly) inward current of mixed ionic nature is a determinant of the spontaneous depolarization that underlies SAN pacemaker activity and thus a modulator of pacing rate $[1,2]$. The $I_{\mathrm{f}}$ channel is constituted by four hyperpolarization-activated, cyclic-nucleotide-gated (HCN) subunits, with the HCN4 protein, which is encoded by the HCN4 gene, as the dominant HCN isoform in rabbit and human SAN [3-6].
Since 2003, several loss-of-function mutations in the HCN4 gene have been associated with human sinus bradycardia [7,8]. For example, Milanesi et al. [9] reported on an Italian family with the S672R mutation. Average resting heart rate (mean \pm SEM) was $52.2 \pm 1.4$ beats/min (range $43-60$ beats/min) in the 15 mutation carriers vs. $73.2 \pm 1.6$ beats $/ \mathrm{min}$ (range $64-81$ beats $/ \mathrm{min}$ ) in the 12 non-affected family members. Similarly, Nof et al. [10] reported on a family with the G480R mutation. The average heart rate of the 8 mutation carriers was $48 \pm$ 12 beats/min, whereas that of the 8 non-carriers was $73 \pm$ 11 beats/min. In three families of Moroccan Jewish decent, Laish-Farkash et al. [11] observed an average heart rate of $58 \pm 6$ beats/min in 14 carriers of the $\mathrm{A} 485 \mathrm{~V}$ mutation and $77 \pm 12$ beats/min in 6 non-carriers.

Only recently, Baruscotti et al. [12] reported on a gainof-function mutation in HCN4. Five family members and carriers of this R524Q mutation exhibited inappropriate sinus tachycardia rather than bradycardia, with a daytime heart rate of $98.5 \pm 14.2$ beats/min (mean \pm SD) in the proband.

The S672R, G480R, and A485V loss-of-function mutations in $H C N 4$ reduce resting heart rate by $\approx 30 \%$, whereas the R524Q gain-of-function mutation increases it substantially. Voltage-clamp experiments on HCN4 channels expressed in cell lines have revealed changes in the expression and kinetics of these and other mutant channels [13,14], but the functional effects of these changes on SAN pacemaker activity remain unresolved.

In the present study, we attempted to assess the effects of HCN4 mutations on SAN pacemaker activity by incorporating the experimentally identified changes in expression and kinetics of HCN4 channels, conducting $I_{\mathrm{f}}$, in the most recent comprehensive mathematical models of single SAN cells. These are the models by Maltsev and Lakatta [15] ('Maltsev-Lakatta model') and Severi et al. [16] ('Severi-DiFrancesco model'). Both models represent the electrophysiological behavior of a single isolated 32-pF rabbit SAN cell and are based on the large amount of experimental data that have become available over the years, largely obtained in patch-clamp experiments on isolated rabbit SAN cells. 
Table 1. Parameter settings and simulation results.

\begin{tabular}{|c|c|c|c|c|c|c|}
\hline \multirow{2}{*}{ Mutation } & \multirow{2}{*}{ Scaling factor } & \multirow{2}{*}{ Shift (mV) } & \multicolumn{2}{|c|}{ Maltsev-Lakatta model } & \multicolumn{2}{|c|}{ Severi-DiFrancesco model } \\
\hline & & & $\mathrm{CL}(\mathrm{ms})$ & $\Delta \mathrm{f}(\%)$ & $\mathrm{CL}(\mathrm{ms})$ & $\Delta \mathrm{f}(\%)$ \\
\hline Control & 1 & 0 & 332.7 & 0 & 354.7 & 0 \\
\hline P257S & 0.5 & 0 & 340.6 & -2.3 & 409.6 & -13 \\
\hline A414G & 1 & -23.9 & 347.7 & -4.3 & - & - \\
\hline G480R & 0.5 & -15.0 & 347.2 & -4.2 & - & - \\
\hline $\mathrm{Y} 481 \mathrm{H}$ & 1 & -43.9 & 350.9 & -5.2 & - & - \\
\hline $\mathrm{G} 482 \mathrm{R}^{\mathrm{a}}$ & 1 & -38.7 & 350.6 & -5.1 & - & - \\
\hline G482R ${ }^{b}$ & 0.35 & 0 & 343.4 & -3.1 & 444.5 & -20 \\
\hline A485V & 0.33 & -30 & 350.5 & -5.1 & - & - \\
\hline R524Q & 1 & +4.2 & 328.4 & +1.3 & 319.5 & +11 \\
\hline K530N & 1 & -14 & 343.2 & -3.1 & 577.5 & -39 \\
\hline D553N & 0.37 & 0 & 343.0 & -3.0 & 438.8 & -19 \\
\hline S672R & 1 & -4.9 & 336.9 & -1.2 & 402.4 & -12 \\
\hline G1097W & 0.55 & -7.6 & 343.9 & -3.3 & 509.6 & -30 \\
\hline Full block & 0 & 0 & 351.0 & -5.2 & - & - \\
\hline
\end{tabular}

Scaling factor applied to fully-activated $I_{\mathrm{f}}$ conductance. Shift in voltage dependence applied to steady-state activation curve as well as time constant of (de)activation. $\Delta \mathrm{f}$, percent change in pacing rate. ${ }^{a}$ According to Milano et al. [19]. ${ }^{\mathrm{b}}$ According to Schweizer et al. [20].

\section{Methods}

The source code of the Maltsev-Lakatta and SeveriDiFrancesco models $[15,16]$ was taken from the model repository on the CellML website [17]. For consistency and to prevent slow drifts, we set the intracellular $\mathrm{Na}^{+}$ concentration of the Severi-DiFrancesco model [16] to a constant value, as in the Maltsev-Lakatta model [15].

Mutations in HCN4 were implemented by scaling the fully-activated conductance of $I_{\mathrm{f}}$ and/or shifting its voltage dependence, based on the data from literature obtained in voltage-clamp experiments on HCN4 channels expressed in cell lines [13,14]. The scaling factors and shifts are listed in Table 1 (left columns).

The CellML code was edited and run in the Cellular Open Resource (COR) environment [18], version 0.9 .31 .1409 . All simulations were run for a sufficiently long time to reach steady-state behavior.

\section{Results}

\subsection{Maltsev-Lakatta model}

Fig. 1 shows results obtained with the Maltsev-Lakatta model. All loss-of-function mutations result in a decrease in $I_{\mathrm{f}}$ and an accompanying increase in cycle length.
However, the decrease in pacing rate $(\Delta \mathrm{f})$ is limited to only a few percent (Table 1), much less than what might be expected from the aforementioned clinically observed decrease in resting heart rate of $\approx 30 \%$. Similarly, the sole gain-of-function mutation, R524Q, results in an increase in pacing rate of only $1.3 \%$ (Table 1 ).

The small changes in pacing rate point to a typical feature of the Maltsev-Lakatta model: with a slowing of $5.2 \%$, full block of $I_{\mathrm{f}}$ has a marginal effect on pacing rate (Fig. 1, dashed grey lines). This reflects the viewpoint that the contribution of $I_{\mathrm{f}}$ to heart rate regulation is only modest [21], which is subject of an ongoing debate that will not be repeated here.

\subsection{Severi-DiFrancesco model}

Next, we carried out simulations with the SeveriDiFrancesco model. The observed effects of mutations in HCN4 are much larger than with the Maltsev-Lakatta model (Fig. 2), up to a decrease in pacing rate of $39 \%$ for the K530N mutation (Table 1). However, pacemaker activity ceases for 5 out of the 11 loss-of-function mutations tested (Fig. 2). Pacemaker activity also ceases upon full block of $I_{\mathrm{f}}$. This illustrates a typical feature of the Severi-DiFrancesco model: pacemaker activity is critically dependent on $I_{\mathrm{f}}$. Thus, $I_{\mathrm{f}}$ surely has "a major pacemaking role" [22]. 


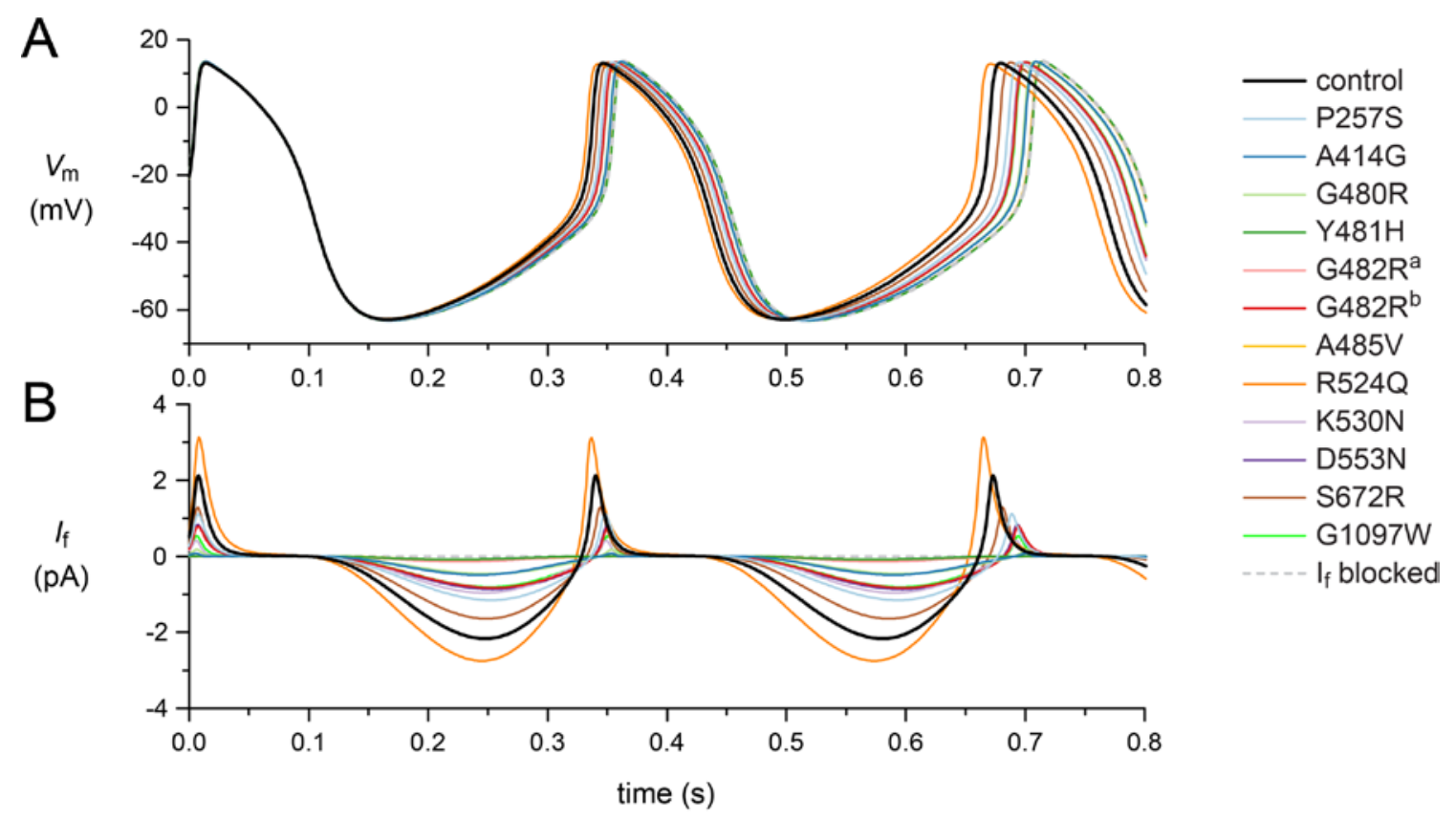

Figure 1. Effect of heterozygous mutations in HCN4 on pacemaker activity in the Maltsev-Lakatta rabbit SAN cell model. (A) Membrane potential $\left(V_{\mathrm{m}}\right)$. (B) Associated hyperpolarization-activated 'funny current' $\left(I_{\mathrm{f}}\right)$.

\subsection{Unification of $I_{\mathrm{f}}$ equations}

If we replace the $I_{\mathrm{f}}$ equations of either model by the ones that we recently derived from our experimental data on rabbit SAN cells [23], the above results become even more distinct: the Maltsev-Lakatta model shows even smaller changes in pacing rate, whereas pacemaker activity of the Severi-DiFrancesco model now even ceases under control conditions (data not shown).

\section{Conclusion}

The two most recent comprehensive mathematical models of single SAN cells show widely different results upon implementation of mutations in the HCN4 funny current gene. We conclude that these models do not allow adequate investigations of the functional effects of mutations in HCN4.

\section{References}

[1] Baruscotti M, Barbuti A, Bucchi A. The cardiac pacemaker current. J Mol Cell Cardiol 2010;48:55-64.

[2] DiFrancesco D. The role of the funny current in pacemaker activity. Circ Res 2010;106:434-46.

[3] Shi W, Wymore R, Yu H, Wu J, Wymore RT, Pan Z, Robinson RB, Dixon JE, McKinnon D, Cohen IS. Distribution and prevalence of hyperpolarization-activated cation channel (HCN) mRNA expression in cardiac tissues. Circ Res 1999;85:e1-6.
[4] Tellez JO, Dobrzynski H, Greener ID, Graham GM, Laing E, Honjo H, Hubbard SJ, Boyett MR, Billeter R. Differential expression of ion channel transcripts in atrial muscle and sinoatrial node in rabbit. Circ Res 2006;99:1384-93.

[5] Brioschi C, Micheloni S, Tellez JO, Pisoni G, Longhi R, Moroni P, Billeter R, Barbuti A, Dobrzynski H, Boyett MR, DiFrancesco D, Baruscotti $M$. Distribution of the pacemaker HCN4 channel mRNA and protein in the rabbit sinoatrial node. J Mol Cell Cardiol 2009;47:221-7.

[6] Chandler NJ, Greener ID, Tellez JO, Inada S, Musa H, Molenaar P, DiFrancesco D, Baruscotti M, Longhi R, Anderson RH, Billeter R, Sharma V, Sigg DC, Boyett MR, Dobrzynski H. Molecular architecture of the human sinus node: insights into the function of the cardiac pacemaker. Circulation 2009;119:1562-75.

[7] Baruscotti M, Bottelli G, Milanesi R, DiFrancesco JC, DiFrancesco D. HCN-related channelopathies. Pflügers Arch 2010;460:405-15.

[8] DiFrancesco D. Funny channel gene mutations associated with arrhythmias. J Physiol 2013;591:4117-24.

[9] Milanesi R, Baruscotti M, Gnecchi-Ruscone T, DiFrancesco D. Familial sinus bradycardia associated with a mutation in the cardiac pacemaker channel. N Engl J Med 2006;354:151-7.

[10] Nof E, Luria D, Brass D, Marek D, Lahat H, Reznik-Wolf H, Pras E, Dascal N, Eldar M, Glikson M. Point mutation in the HCN4 cardiac ion channel pore affecting synthesis, trafficking, and functional expression is associated with familial asymptomatic sinus bradycardia. Circulation 2007;116:463-70.

[11] Laish-Farkash A, Glikson M, Brass D, Marek-Yagel D, Pras E, Dascal N, Antzelevitch C, Nof E, Reznik H, Eldar 


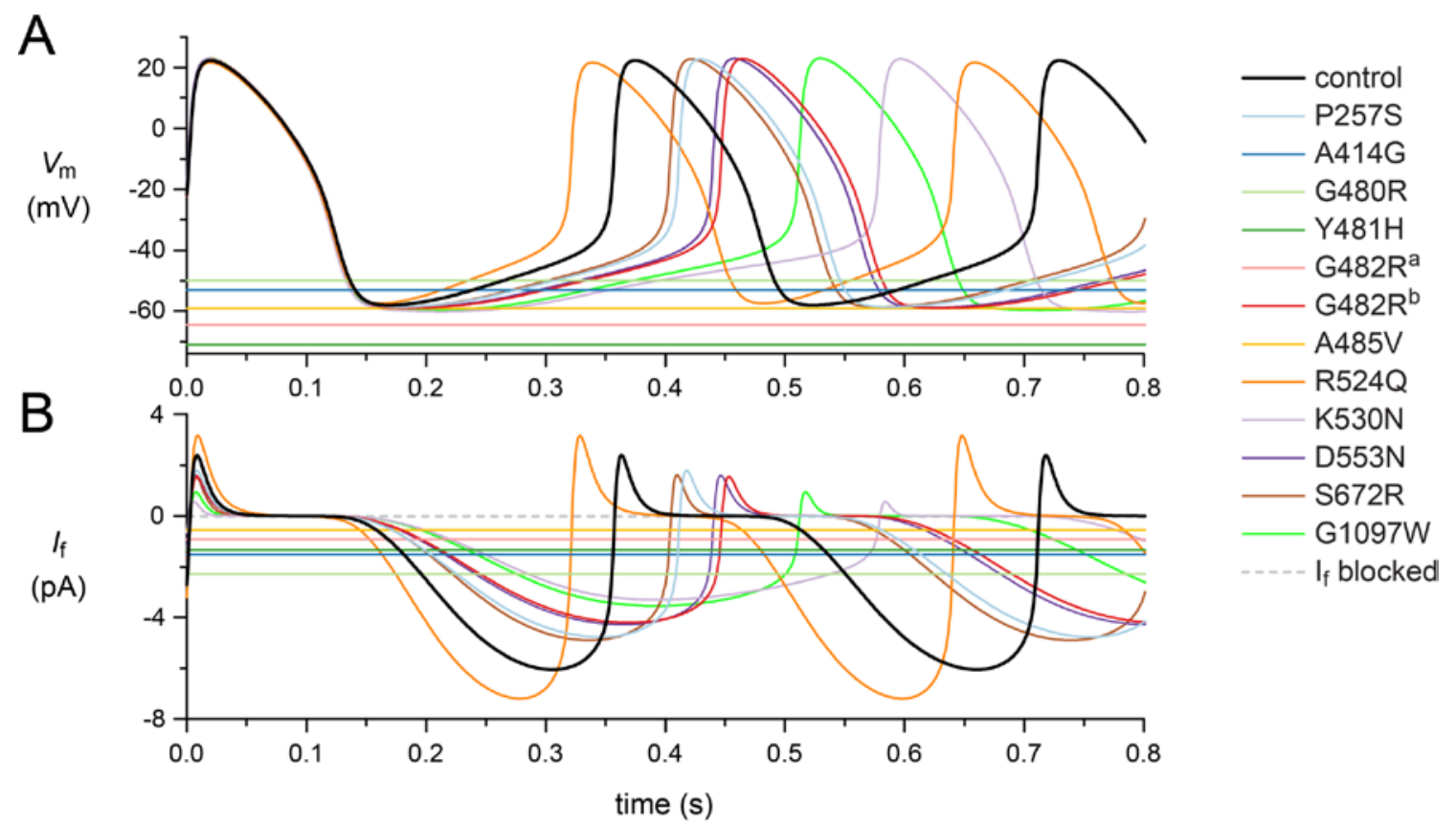

Figure 2. Effect of heterozygous mutations in HCN4 on pacemaker activity in the Severi-DiFrancesco rabbit SAN cell model. (A) Membrane potential $\left(V_{\mathrm{m}}\right)$. (B) Associated hyperpolarization-activated 'funny current' $\left(I_{\mathrm{f}}\right)$. Pacemaker activity ceases in 5 out of 11 loss-of-function mutations tested.

M, Luria D. A novel mutation in the HCN4 gene causes symptomatic sinus bradycardia in Moroccan Jews. J Cardiovasc Electrophysiol 2010;21:1365-72.

[12] Baruscotti M, Bucchi A, Milanesi R, Paina M, Barbuti A, Gnecchi-Ruscone T, Bianco E, Vitali-Serdoz L, Cappato R, DiFrancesco D. A gain-of-function mutation in the cardiac pacemaker HCN4 channel increasing cAMP sensitivity is associated with familial Inappropriate Sinus Tachycardia. Eur Heart J (in press).

[13] Verkerk AO, Wilders R. Pacemaker activity of the human sinoatrial node: effects of HCN4 mutations on the hyperpolarization-activated current. Europace 2014;16: 384-95.

[14] Verkerk AO, Wilders R. Pacemaker activity of the human sinoatrial node: an update on the effects of mutations in HCN4 on the hyperpolarization-activated current. Int J Mol Sci 2015;16:3071-94.

[15] Maltsev VA, Lakatta EG. Synergism of coupled subsarcolemmal $\mathrm{Ca}^{2+}$ clocks and sarcolemmal voltage clocks confers robust and flexible pacemaker function in a novel pacemaker cell model. Am J Physiol Heart Circ Physiol 2009;296:H594-615.

[16] Severi S, Fantini M, Charawi LA, DiFrancesco D. An updated computational model of rabbit sinoatrial action potential to investigate the mechanisms of heart rate modulation. J Physiol 2012;590:4483-99.

[17] Cuellar AA, Lloyd CM, Nielsen PF, Bullivant DP, Nickerson DP, Hunter PJ. An overview of CellML 1.1, a biological model description language. Simulation 2003; 79:740-7.

[18] Garny A, Kohl P, Noble D. Cellular open resource (COR): a public CellML based environment for modelling biological function. Int J Bifurcat Chaos 2003;13:3579-90.
[19] Milano A, Vermeer AMC, Lodder EM, Barc J, Verkerk AO, Postma AV, van der Bilt IAC, Baars MJH, van Haelst PL, Caliskan K, Hoedemaekers YM, Le Scouarnec S, Redon R, Pinto YM, Christiaans I, Wilde AA, Bezzina CR. HCN4 mutations in multiple families with bradycardia and left ventricular noncompaction cardiomyopathy. J Am Coll Cardiol 2014;64:745-56.

[20] Schweizer PA, Schröter J, Greiner S, Haas J, Yampolsky P, Mereles D, Buss SJ, Seyler C, Bruehl C, Draguhn A, Koenen M, Meder B, Katus HA, Thomas D. The symptom complex of familial sinus node dysfunction and myocardial noncompaction is associated with mutations in the HCN4 channel. J Am Coll Cardiol 2014;64:757-67.

[21] Maltsev VA, Lakatta EG. Funny current provides a relatively modest contribution to spontaneous beating rate regulation of human and rabbit sinoatrial node cells. J Mol Cell Cardiol 2010;48:804-6.

[22] DiFrancesco D, Noble D. The funny current has a major pacemaking role in the sinus node. Heart Rhythm 2012;9: 299-301.

[23] Verkerk AO, Wilders R. Hyperpolarization-activated current, $I_{\mathrm{f}}$, in mathematical models of rabbit sinoatrial node pacemaker cells. Biomed Res Int 2013;2013:872454.

Address for correspondence:

Ronald Wilders, $\mathrm{PhD}$

Department of Anatomy, Embryology and Physiology

Academic Medical Center, University of Amsterdam

Meibergdreef 15, 1105 AZ Amsterdam

The Netherlands

Phone: +31-20-5665229

E-mail: r.wilders@amc.uva.nl 